Arte, Individuo y Sociedad

ISSN: 1131-5598

http://dx.doi.org/10.5209/ARIS.55278

\title{
Carolyn Halpin-Healy on her experience as Co-Founder and Executive Director of Arts \& Minds in conversation with Sara Torres.
}

\section{Introduction to arts \& minds}

Q: Could you briefly introduce Arts \& Minds?

A: Arts \& Minds is a not- for-profit organization and our goal, our mission, is to improve well-being for people living with dementia and their caregivers through meaningful contact with art. We set out to do that in 2010 by partnering with the Studio Museum in Harlem and later, with the New York Historical Society, El Museo del Barrio and also with the Metropolitan Museum of Art. We have 3 core partners and a special partnership with the Met, with whom we implement local programs serving people with dementia and their caregivers here in New York City. And we are also involved in training and consulting with museums in other places. We have a 21-hour Training Course that I take to museums to help them establish their own programs to serve the local population in their cities or towns. We've helped start programs in New Orleans; Dubuque, Iowa; and now we're working with the Smithsonian and the National Gallery of Art in Washington.

\section{Origins of arts \& minds}

Q: I see that you are developing long-term relationships with the participants. When did that relationship start? I'm thinking of the complexity of putting together the museum, a non for profit organization such as Arts \& Minds and the potential participants. How did the first group gather and experience the program?

A: This is a historical question, which has certain complexities. When Dr. Noble ${ }^{1}$ asked me to work with him, it was because he came to Met Escapes at the Metropolitan Museum of Art and he was inspired by what he saw in that program and he thought that it could make a difference for his patients. At the time, he was about to take up his clinical appointment at Harlem Hospital and at The Met he noticed few people of color in the room except the professional caregivers and at Harlem Hospital they are serving the largely African American community above $125^{\text {th }}$ street. So that was a concern. There was no program above $82^{\text {nd }}$ street at that time and there was nobody

\footnotetext{
James M. Noble MD, James M. Noble, MD, MS, CPH.

Assistant Professor of Neurology at Columbia University Medical Center, Taub Institute for Research on Alzheimer's Disease and the Aging Brain.

G.H. Sergievsky Center, Department of Neurology.
} 
specifically targeting African Americans or Hispanics. In the US, both groups have a higher incidence of Alzheimer's disease and dementia than non-hispanic whites. Typically, communities that may historically live in poverty are more profoundly impacted by Alzheimer's disease and dementia. Minority communities are also more profoundly impacted by diabetes, stroke, and heart disease. All the stress-related diseases impact the poor and people of color. So this was a priority for Dr. Noble and a priority for me. And why for me? It comes from a lifelong concern about social justice and fairness so I was really happy to partner with him. Being a museum professional, I approached the Studio Museum in Harlem where Shanta Lawson is my colleague and now the Education Director there. We made a commitment to work together to figure out how to do this program. First we had to get the commitment of the museum. Then, we got a small grant from the Friends of Harlem Hospital to fund the initial pilot and then it was a matter of outreach to potential participants. We reached some through the Neurology Clinic at Harlem Hospital, and we also did a broader outreach through local churches. We also went to some community organizations. Social Workers at the Abyssinian Development Corporation, which serves youth and elders in all kinds of social programs were particularly helpful. Going to churches was pretty intuitive. In the Black community it is a place to go if you want to get the word out on anything. It is an important community resource and the churches are powerful social centers. Oftentimes pastors are well aware of the needs of the community so a pastor may put us in touch with the other members of the community or with those people that see signs of dementia beginning perhaps.

Q: You are dealing here with any different things. This particular audience, plus community needs and getting to know which ones are more affected by Alzheimer's disease and dementia. There is a social need there and you take the step forward.

A: As you know, there is also a lot of fear and stigma associated with Alzheimer's disease. In the black community, there might be more fear and stigma. The understanding among the public at large, of dementia and normal aging is not necessarily clear. So people may see dementia in their family but not understand that it is not normal aging. They may think "well grandma is just old and that's how old people are: they can't remember anything, they get lost, they put their shoes in the freezer". They just don't know that that's not normal aging. So to actually do the outreach, to find the people in need, you know, we knew they were there from the population studies. We know they are there from Dr Noble's clinical practice at Harlem Hospital. And yet there are only a limited number of individuals that can be reached directly through the clinics. And others... we want to find those people and it is not always so easy. So the churches are a sort of tried and true way.

Now since then, we have started a program with El Museo del Barrio. The Spanish speaking community in New York is quite diverse. The older Spanish speaking population is largely made up of those who came to the US in the 1950s, ' 60 s and '70s. They are largely Dominican and Puerto Rican and they came to East Harlem, to "El Barrio." Now, the newer waves of Spanish speaking immigrants are coming from Mexico and we've got you (Sara) coming from Spain! They are coming from Colombia as well and many other places, and so we have other kinds of networks that we have to figure out to tap into. In East Harlem there is a network of senior centers and some really dynamic social workers there. For East Harlem, to reach 
the Spanish speaking community, we went not to churches but through a network of social work connections. Those people have their ways of reaching people on the ground. That's where we depend on them to make our programs known to that community. And it is a very slow process. You would be amazed!

Q: The very first session, how was it? How did you plan for it?

A: The very first session in 2010 , the pilot... It was really exciting! We had about five people with dementia and five caregivers. Most of the participants were visiting the Studio Museum for the first time. Shanta and I are very experienced museum educators and I had worked with people with dementia already at The Met. I had also done a lot to educate myself about dementia. I went to a training course at The Alzheimer's Association to become a support group leader and though I never started a traditional support group, I used that teaching and all of those materials to inform myself because we do in fact function in a supportive role. Even though we are not doing anything like therapy. In the programs we are not talking about Alzheimer's disease - . we are decidedly not talking about it. We are talking about something else - art! That first group of individuals had a variety of different dementias, different diagnoses. And they were mostly from Harlem Hospital. And we had a very open and collaborative partnership because of my and Shanta's commitment as educators to be participant-led. From the beginning we were noticing the participants' responses, understanding how they interacted, looking carefully at how we implemented the program. They helped us very much to learn about what we were doing.

Q: Did you plan the itinerary in advance or were you completely led by the participants' interests?

A: It was planned in advance with the idea that it could change. You always prepare five works for a session when it's likely that you'll work with three or four. In this early stage we also worked with a teaching artist named Sarah Mostow, who is still part of our team. Sarah is a progressive teaching artist, who has worked largely with children and is an excellent museum educator with a deep understanding of an inquiring approach. That is an open ended way to foster aesthetic experience and a dialogue of response and interpretation. What we are really interested in is dialogue. Because you know, it's not important to me to teach people with dementia the fact that this beautiful print (gesturing to the work hanging nearby) is by Andy Warhol and he made it whenever he made it, the colors and techniques he used, etc. etc. I have to know all of that and if the participants want to know it, I want to share it. But the exchange and the interpersonal dynamic is much more about providing an opportunity for people to experience the work of art as they do, in a dialogue of collective looking. So, through collective looking, we discern what an object might be saying to us, what do they hear it saying, what does it mean to us now? What it means to me can be different from what it means to you. And that's very interesting in the dialogue. 


\section{Current practice: evolution and changes}

Q: At present, what's the relationship with Columbia University like?

A: The relationship with Columbia University is as follows. My co-founder, Jamie Noble, is a volunteer president of the Board of Directors of the organization. So, strictly speaking, this is an independent sort of side-project for him. That said, we are now being invited by the Department of Aging and Dementia and the Taub Institute to work more closely with them as they begin to seek ways to support their patients more fully. That's where the Metropolitan Museum also comes in. We are starting a program that will serve Columbia patients specifically. We are targeting people with mild cognitive impairment or early Alzheimer's disease or other kinds of dementia. It's primarily for people who are in the early stages. And they might even be people who have only recently received a diagnosis. What we are hoping to do is to bring them into the museum space to have them imagine what they might be able to do as people who now are carrying this devastating diagnosis. We want to get people before they despair, before they take themselves out of intellectual or social or artistic activities, and demonstrate to them by their participation, that there is a lot that they can still do that is interesting and worthwhile.

\section{Q: Do you work with late stage?}

A: Arts \& Minds does work with people in late stages. We began by targeting people in early to mid-stage. But as you know people can live for a very long time with this disease and so now, we have participants with us who have been attending since 2010. One individual that I'm thinking of had mid-stage symptoms in 2010 . Now his symptoms are quite advanced but he and his wife are attending the program whenever they can. For people like him, who exhibit advanced symptoms of dementia we differentiate our approach. At each of our museums, we are serving people who are more severely affected in one group and those in earlier stages in another group. This is because individuals at different stages of dementia have different cognitive and social capacities. We work hard to address each person where they are and it is important to recognize both abilities and limitations. That's our challenge and it's also our commitment. We are committed to accompanying people for as long as they wish to be with us and for as long as the programs are helpful to both the caregiver and the person with dementia.

Q: What happens when sadly the person living with dementia dies and the connection with the caregiver is no longer there?

A: This plays out in different ways. One person became a member of our Board of Directors after her mother passed away, though it is more typical that the care partner withdraws from Arts \& Minds. They move on to another phase of life. But there is usually some transition phase where they may come back to visit or they may join us at another venue or I might meet with them independently. The door is open to them and they are always welcome to come and be with us if they wish. 
Q: In terms of producing meaningful dialogue and considering the variation in communication skills, depending on each participant's condition: how do you provide for the right atmosphere for the dialogue to happen? I know this is a very abstract question...

A: It is also a very basic and practical question. It is about how it plays out, right? The programs are built around the work of Tom Kitwood who wrote a book called Dementia Reconsidered: The Person Comes First (1997). Kitwood was looking mostly at nursing homes systems and developing the model of person centered care. $\mathrm{He}$ is really the forerunner of person centered care, as you may know. If you recall Sara, his diagram of needs, do you remember that? It looks like a flower. At the center is love.

[Sara, would you want to include this diagram here? Here it is, in case you think this is a good idea. Here is the reference: The main psychological needs of people with dementia. Tom Kitwood, Dementia Reconsidered: The Person Comes First, Open University Press, 1997.\}

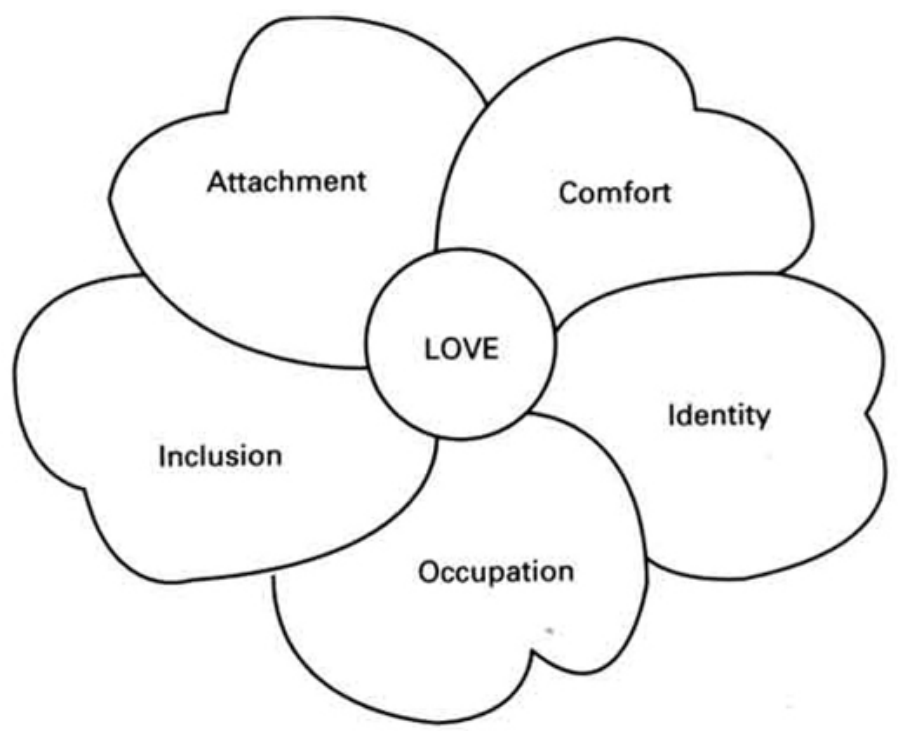

Q: And it is a diagram you could use for any audience in a way.

A: In a way, yes! He proposes it for people with dementia but really it's all people, right? He talks about inclusion, identity, attachment, comfort and occupation. It is through a commitment to meeting the person wherever she or he might be: Everyone is warmly invited - the human warmth, the handshake, looking you in the eye, calling you by name, all of these things, make a person feel welcome and safe so a lot of effort goes into creating the right tone. And it is a tone of warmth and welcome and seriousness about what we are doing. Occupation is another basic need. Our occupation is about looking at works of art together and this is worth doing. It is something that humans do. Let's continue to do it although we are living 
with dementia and caregiving. We have had very diverse participants - people who can express themselves verbally and those who cannot. And it is challenging. There's a lot more to talk about, but it is really just about these things: About looking a person in the eye, about waiting, about mirroring back what that person has said, or maybe I'm not repeating a word, maybe I'm mirroring a facial expression. "I see you smiling Isabel. Are you smiling at the orange in this painting?." It's in this way that someone who is not speaking can be involved and validated, and sense that she is heard.

Q: We have talked here about art appreciation and being in touch with the work of art. How about art making sessions?

A: The typical Arts \& Minds program involves about half an hour of dialogue with the work of art in the gallery followed by hands on art making in the workshop. Have you come to a session?

Q: I went to the one at the Met.

A: Met Escapes, OK. So you'll come to Arts \& Minds after you defend your thesis. (laughs). First there is a dialogue with a single work of art led by the museum educator. Then the group retires to an art making space, to a studio space for a hands on art making experience.

Q: To avoid misunderstandings: the Met is not part of the Arts \& Minds network, is it?

A: The core programs of Arts \& Minds are at the three smaller museums: The Studio Museum, the New York Historical Society and El Museo del Barrio. We partner with the Met on other initiatives, such as our new program for Columbia patients. Meanwhile The Met has been running Met Escapes since 2008. That's where I first encountered this audience. I like to think of The Met as the fairy godmother of Arts \& Minds. Met Escapes is Met administered and Met facilitated by really excellent people.

Q: So you were telling me the structure of a session. First you go and see only one artwork.

A: Typically, it is a single work..

Q: Because before in the conversation you told me that there were five so, there is an evolution, right?

A: Yes. There has been an evolution. Initially, we experimented with two program formats. The first was gallery only and that involved 3 or 4 works of art in a 90 minute session. The other format consisted of half an hour of collective looking followed by art making. The participants requested more art making, so for several years we have adhered to the format that incorporates time in the gallery followed by time in the workshop. 
Now that we are staying with the people in more advanced stages we have returned to the gallery only format. We are developing gallery based hands-on activities. The people who comes to these groups may no longer be able to hold a paint brush. They certainly can't make a collage because there is so much procedural memory involved. You have to turn the paper over, you have to dip the brush into the glue, you have to get the glue to the paper, you have to turn it back over... there are many, many steps in that process. A person in advanced dementia... many cannot do that. Many of them cannot speak and many of them are no longer walking. Those with very advanced symptoms tend to be very elderly. Many are in their late eighties and some are in their early nineties. What that means is we need to have a shorter program for them. A ninety-minute program is too long. It's too tiring. The original format of being in the gallery and then going to the workshop, and then coming out to leave the museum at the end of the program involved too many transitions. We could see that was making people uneasy and of course, we want to reduce anxiety. So, for participants with advanced symptoms, we no longer go to the workshop. We stay in the gallery the whole time, which is wonderful because we are in the museum space and we have the art around us. Together with my teaching artists, we are trying to conceive ways to involve people, that may include hands-on work, or it may involve music or poetry. We're experimenting with how make that happen in the gallery. And so once again we prepare quite a few works of art and a number of activities and then we see what works.

Q: In the art-making process, do the caregivers do their own creation or do they collaborate on the person with dementia's creation?

A: For this group, where people are more severely affected, we set it up so that it is more of a collaborative activity for the care partners or even a whole group activity such as writing a poem.

Q: Is that why you have teaching artists? Is it because of the interdisciplinary activities?

A: Yes. The reason for this is because you need to have a depth of experience if you are going to facilitate an art making activity and trained artists have that. What we want to avoid, is "artsy craftsy" activities. Craft is great. It has a very important role in life and in the world. But ours is an art program and there is a distinction. There are elements of craft in making, certainly, but we are working with drawing, painting and collage rather than say knitting, wood carving or any other traditional craft The people who facilitate programs for Arts \& Minds are already teaching for the partner museum. The reason I choose them is because we need professionals who know the collection and who know the modus operandi of each of the museums. They know their art history and they also know materials and art making. I believe very strongly that we have to go for the highest quality in terms of teaching and the materials offered in order to have the best program possible. High quality materials are a sign of respect to the participants and their art work. We are working in museums for that very reason. Because once you are in a museum space, the expectation of 
quality is already at a much higher level. I am really committed to art and I am really committed - deeply, deeply committed to respecting the interaction of any individual and the work of art.

Q: The training of these teaching artists and the training you provide to other institutions, how do you organize that? How do they get in touch with you? And what is the curriculum?

A: This is also something that has evolved over time because when we started we were sort of teaching ourselves, I did a great deal of research and I went to the the Alzheimer's Association to learn everything I could and I was talking at length with my co-founder Dr. Noble to develop the understanding of dementia that would inform our programs. I took graduate courses in adult development and adult learning. Colleagues at MoMA were very generous in shaing the lessons of their work in Meet Me at MoMA. At this point, 7 years in, we have developed significant expertise based on knowledge of art and art history, dementia and dementia care, adult learning theory, critical education theory, social work and public health. The work is very interdisciplinary. I've developed a 21-hour training course, which Arts \& Minds teaching artists and volunteers have all gone through and which we are now sharing with other museums around the country. ${ }^{2}$ I think of the training program in two parts: Knowledge and Action. We assume that the museum staff and volunteers come with knowledge of their collections and deep knowledge of their subject. We add to that a number of topics including theory of person-centered care; symptoms and behaviors of Alzheimer's and other dementias; emotional needs of people with dementia; needs of professional and family caregivers; communication strategies and so on. I then coach the educators to put this new knowledge into action in their museum. We work on Identifying art for program focus; facilitating dialogue; managing the audience dynamic; developing art activities; and adapting dialogue and art making strategies. It is about putting knowledge and theory into practice. Finally, I work with the team on the nuts and bolts of welcoming people with dementia and their caregivers to the museum. I share information about the procedures that will insure the success of the program - everything from learning a bit about the participants in the registration process to welcoming them properly when they arrive, providing comfortable seating, transitioning within the museum and finally concluding the program in a satisfying way. We always want to send participants out on a high note.

\footnotetext{
Arts \& Minds was founded specifically to address the dementia care needs of underserved communities. The approach is multi-faceted, combining art viewing, conversation, and art making to inspire creativity. The programs are designed to address symptoms of apathy, unpredictable behavior, and other cognitive and behavioral changes. With expert facilitation by trained professional teaching artists and educators, and among others sharing similar challenges, art can tap into emotion, memory and imagination. Research shows improved mood for both individuals with dementia, and for caregivers, as well as reduced apathy for individuals with dementia and reduced isolation and stress for caregivers. For older adults, involvement in participatory art activities reduces falls, doctor visits, and medication use, while supporting overall health and boosting morale. Arts \& Minds participants benefit from the stimulation of cognitive functions and increased rapport with other people. In addition, the museums reach a new audience and serve vulnerable members of the community. By connecting professionals, patients and museums, Arts \& Minds ameliorates the fear and stigma of Alzheimer's disease and contributes to a world where, in the absence of a cure, it is possible to live well with dementia.
} 


\section{Q: How do you approach art-making?}

A: What we are looking for in the art making is the analogue to the gallery experience. We offer an approach that is open-ended and which is ultimately about meaningmaking. Taking this approach is another way to respect the participant and to trust the materials and to trust that you'll be able to frame an activity that will elicit a real art-making effort from the participants. This stands in contrast a kind of step-by-step approach that has a predetermined outcome. So when I approach a painting in the gallery with a group of participants, I don't immediately know where the dialogue is going because, perhaps it is the first time they are there together and it's a new day and it's a fresh work of art, and everything changes. That kind of willingness to be surprised, the willingness to put it very much into the hands of the participants and to have a light hand on the steering wheel, so to speak, is what we try to do in the studio as well. So we'll offer materials that are carefully selected and prepared based on the object we have discussed in the galleries. There is a kind of a framing or motivating question, which the teaching artist has considered very carefully, usually in conversation with me or a colleague. And then people are given time to make things with the support of the teaching artist and volunteers. At the end of the session everything that people have made is posted on the wall and it receives the same attention that the work in the gallery received. We look and share and make observations and listen to the maker if that person wants to say anything about what she's made. It's often the best part of the program!

Q: There is a sense of risk-taking in this process... people may look at the materials, listen to the provocation or question and then say... what do I do?

A: Yes, some may not know how to approach the materials and they certainly don't know the outcome. Some may also be resistant to participating at first. The idea is to provide enough of a frame and some encouraging guidance. We are not just handing people supplies and telling them to paint whatever they wish because that creates anxiety and they need support in order to succeed. We are providing a motivating question and it might be something quite abstract that has grown out of the dialogue in the gallery. For example, it could be, "When do you feel free?" That could be something. "How might you make your mark?" "How might you use these materials to make a painting today?" The connection there, between the framing question and the gallery inquiry has to do with meaning making. Worthwhile occupation has to do with meaning making. What does this work of art mean to the artist? To you? To me? What does the art that I make now mean to me? And it might be something profound, but it might just be... "I really like pink!"

Q: You have to be very brave to do that. To have that sort of confidence.

A: I don't think the people would say necessarily that they are brave, but you're right, there is some risk involved. Some participants can be quite tentative at the beginning, but confidence usually developes over time. Some people like to draw, they love to make marks and their work is self-expressive There is sensory pleasure as well - the pleasure of the feeling of charcoal or the flow of watercolor on a beautifully textured 
paper. We always want to keep the aesthetic alive and we always want to be helping people to make what they need to make.

Q: On your website there is a section named "Research". Why is that?

A: Why are we doing that work? Well, because we are curious! We want to understand the ways and extent to which the programs are helping people. My cofounder is a physician. He and his students are interested in the impact on patients: Is it reducing apathy? It seems that it is. Is it reducing caregiver burnout? It looks like it probably is. A study they published last year demonstrated that attendance at an Arts \& Minds program may positively influence dementia attitudes of pre-clinical medical students. (Roberts HJ, Noble JM. "Changing Medical Student Perceptions of Dementia: An Arts-Centered Experience" Neurology April 8, 2014 vol. 82 no. 10 Supplement P1.318) This was an exciting result that was published in Neurology and which was also the subject of an editorial (Childress, Marcia Day and Donna Chen. "Art and Alzheimer Dementia: A museum experience for patients may benefit medical students" Neurology 2015;85:663-664

1. )

My own work is more in the realm of Museum Studies. I am interested in the benefits of aesthetic experience and in the role of museums in society. (HalpinHealy, Carolyn. "Report from the Field: Multi-cultural Dialogue and Transformative Learning in Arts \& Minds Programs at The Studio Museum in Harlem," Museum \& Society, March 2015, Vol 13, No 2. ) I am working on an article for the Journal of Museum Education about how we select museum objects for a program.

Q: It is very interesting listening to your reflections on how you do position yourself between the museum studies, the therapy... could you explain a bit more about where do you position yourself?

A: Yes. We are in the space between clinical care and art and we bring them together in museums.

Q: Where do you find your framework?

A: It comes from progressive approaches to museum education. It comes from a deep curiosity about what happens in a dialogue of collective looking, because to me it feels really magical when there is the kind of aesthetic experience that takes you outside of yourself. That to me is magical and I am very curious about it. I read John Dewey and Thomas Merton the catholic spiritual writer, who have important things to say about art. I don't really know where the answer comes from. Does it come from Aesthetics? Philosophy? Religion and Spirituality? Medicine? Social Work? Psychology? I think each of these fields has a way of speaking to what we are trying to do. I'm just trying to figure it out so we can do it even better. It certainly isn't a simple recipe. It is very subtle and complex and it takes a certain amount $\mathrm{f}$ intuition and experience to facilitate a meaningful experience. The important this is to keep art right a the cente alongside knowledge of the audience. 
Q: I'm assuming that you get the recognition you deserve when your participants rely on your work enough to follow your activities throughout years. But how do you feel your position is amongst the scientific community? How do you think this community is understanding your work?

A: First I'll talk about the participants. They may or may not know very much about all of the work that is under the surface. What they see is a program that is meeting their needs and is offered in a way that is thoughtful, that is consciously developed and that is implemented with integrity and care. Yes, they do appreciate that. With regard to the larger community, this depends: are we talking about the museum community? Are we talking about the medical field? Are we talking about social work?

Q: All of those are important but tell me about those communities that you feel it is more important to get approval so as to get recognition and in very practical terms: funding

A: There is a tension in the medical community, which is really about time limitations. I don't think anybody would say "don't do that, you are harming a patient" but they might not necessarily want to jump in and say "absolutely, let's get as many people involved in social activities as possible". There is a scientific literature, coming largely from the fields of psychology and gerontology, that shows the potential of museum programs and creative arts to support well-being for people with dementia and for caregivers. There are studies of various kinds but it is really, really hard to get traction because those who are working in Alzheimer's disease research want to cure the disease. So the resources are quite rightly going in that direction. What we are saying is "that's great!" "that has to happen" but meanwhile people are living with $\mathrm{AD}$ for three to twenty years post diagnosis. So let's figure out a way to help them live well. It doesn't cost much.

The Creative Aging Movement as a field is about 30 years old now and there is an early paper that demonstrated among well older adults that participation in professionally facilitated art activities results in fewer falls, use of fewer medications, and better general well being. (Cohen, Gene D., Susan Perlstein, Jeff Chapline, Jeanne Kelly, et. al. "The Impact of Professionally Conducted Cultural Programs on the Physical Health, Mental Health and Social Functioning of Older Adults," in The Gerontologist, vol. 46, no.6, 2006, 726-734.)

What we see particularly in the case of dementia, as I said earlier, is a reduction in apathy in the person with dementia and a reduction in caregiver depression. It has already been reasonably well established that these programs have a benefit for society. We are developing this work at a time when museums are exploring ways to become spaces of greater social inclusion. The disability movement is really pushing at the doors of museums to go way beyond physical accessibility to a much deeper, more meaningful accessibility for all people. And so, it is an exciting time.

Q: How is Arts \& Minds currently funded?

A: We are funded by a combination of grants from foundations and individual donors. 


\section{Q: Do the participants pay?}

A: The participants do not pay. Whether one pays or not is different in different places and it's an interesting consideration. For example I know that in the UK, at the Royal Academy for example where they have a program, they are quite consciously not implementing what they call a charity model. They ask people to pay a small amount, something like three pounds. It is a nominal fee. They believe that by paying a fee, that person is entitled. Their argument is that this gives that person more agency. This is an excellent point that doesn't work so well in this country. Americans are sort of fine with having museums be free for programs like this and it is very important to remove every barrier. Our healthcare system is such that people have many, many expenses and so, if we can provide this creative activity for them and if we can offer it free of charge then that's what we will do. American museums are generous in this way. If a three-dollar admission fee is a barrier, as it is for some people, I want to remove it. Our approach has always been to raise the money ourselves, to initiate the program and to give it away. And we do that to the greatest degree possible. Now that said, some of our participants are in a position to make donations and so they do that very generously during our annual fundraising campaign.

\section{Impact}

Q: What about how this program impacts the museum?

A: That impact is interesting. It seems to happen in a variety of ways. I think the training and experience of working with Arts \& Minds is deeply affecting the facilitators. They tell me that it impacts every other area of their teaching. They teach school children differently now. They teach everyone differently with I think, greater integrity and more forethought. In terms of influence in the museum as an institution, we did a little of study of this. We commissioned an anthropologist and her student to do a study of the staff at the Studio Museum in Harlem. They looked at the staff, who have direct contact with Arts \& Minds and those who have peripheral involvement. Using a questionnaire and semi-structured follow-up interviews, they discovered that the presence of Arts \& Minds opened the staff's eyes to all museum visitors. They are much more visitor conscious because they have interacted with Arts \& Minds and with Arts \& Minds' participants. They have a greater pride in their work. We interact mostly with the security guards and the facilities staff. They see us the most. If you think of what it's like to work in a museum: it's kind of a fun place to work, it's cool, kind of cutting-edge, but what the guards and others are really proud of is that their museum is serving the community. That was pretty thrilling to learn They find increased value in their jobs because of the presence of this program. It's really exciting from the museum point of view. From the public health point of view, what does it mean? It means that that security guard, who may have never known a person with dementia, now has seen quite a few people with dementia. One story I can share is really quite touching: The programs at the Studio Museum in Harlem happen on Tuesday afternoons when the museum is closed. A particular guard was assigned to accompany our group. Fred was with us every Tuesday for years. We 
noticed that sometimes he was very interested in what people were saying about the art. Gradually, Fred became part of the group in a way.. One day, Fred asked us to pose for a picture. He was changing his hours to work on the night shift and he wasn't going to be seeing us anymore. We hadn't known how much the group meant to him. That day, he was hugging people goodbye in the elevator. It was so touching. I think the programs mean a lot at a human level, the social justice level of making spaces accessible to people, to everyone, for everyone to be seen and heard. From the public health point of view, if dementia shows up in Fred's family, he might not be so scared. And he might take that family member to the doctor to find out what's going on.

I really feel that it is important work. It is still very small though, Sara. It is great that many museums are doing this, it is wonderful that you are trying to get this going in Spain, but we have some tough practical issues and there will be more, so how are we going to do this?

It's about art and it is about education. And those two things feed the human spirit.

Q: What are the pros and cons of working from the outside of museums?

A: The great pro of that is that we are bringing a resource to a museum that wouldn't otherwise be able to do program like Arts \& Minds. They don't have the internal resources; they might not have the expertise. So we bring that, along with the experience and the practical knowledge. And this allows a museum like El Museo del Barrio to say "we are doing the first program in Spanish in the country!" That's a great advantage. One of the challenges is that in some places, it may not be a priority of the museum. I think I've learnt how to avoid that now, how not to get involved with people who don't value it highly enough. Most often, I have approached a museum through the education department, where they understand the inherent value of inclusion. But sometimes it is necessary to go to the director's office and have it happen that way. And even then, you never know. In small museums the Board of Directors can have an immediate impact, which can be very positive or perhaps less supportive. The museums determine their own priorities and we are very mindful of aligning our programs with the mission of the museum.

\section{Q: Is there anything you would like to explain? Any final thoughts?}

A: One thing I would like to do is to bring in the voice of individuals with dementia. I speak frequently at conferences and panels and so on and there is a need to involve not only caregivers but also people with dementia. In the disability rights movement there's a phrase "nothing about us without us." We need to include people with dementia. I think part of making that happen may be to conceptualize dementia as a disability. In this country Alzheimer's is thought of first and foremost as a fatal disease. Illness and disability are related, they are overlapping, but they are different things. It seems to me that concepts of disability - social models of disability and also medical models of disability are about living. It's about where impairment of the body meets the world, right? Where it meets the social structure. That feels to me qualitatively different from fatal illness. I'd like for people to be able to think of "living with" instead of "dying from." The cultural narrative of Alzheimer and dementia in this country is really dark. It's about continued diminishment and on 
some level that's just wrong! This is an arguable point, but where I object to it is in how this point of view affects the way we treat people. One hears the phrase "loss of personhood". One hears this in medicine, you hear it all over the place. And even well-meaning people will use that phrase and I think that's just horrible. Because as long as you are a person, you are a person! You don't lose your personhood. You may not be able to speak, you may not be able to walk, but your human integrity must always be there. The challenge is for those of us who do not have dementia, to learn how to support that person, interact with that person, and value what that person brings. I would like to see more of that. And I think we are just at the beginning of bringing the voice of people with dementia to the discussion.

Q: You make personal change in people's lives, you make an impact in the museums, changing society is probably the highest goal in terms of how dementia is perceived.

A: I hope that by creating opportunities for people with dementia to be in museums, engaging with art and one another in the public space, we will all come to realize that we have much to learn about being in the here and now - with art and with one another. 